To cite this article: Niranjana, K, Tolessa Desta \& Paul N. Vijaya Kumar (2020) Implementation of KOHA Integrated Library Management System in Wollega University Main Library, Nekemte, Ethiopia. Information Impact: Journal of Information and Knowledge Management, 11:4, 69-80, DOI: https://dx.doi.org/10.4314/iijikm.v11i4.7

To link to this article: https://dx.doi.org/10.4314/iijikm.v11i4.7

\title{
Implementation of KOHA Integrated Library Management System in Wollega University Main Library, Nekemte, Ethiopia
}

\author{
${ }^{1}$ Niranjana, K \\ ${ }^{1}$ Tolessa Desta \\ ${ }^{1}$ Paul N. Vijaya Kumar \\ ${ }^{1}$ Department of Information Science, Wollega University, Nekemte, Ethiopia
}

\begin{abstract}
KOHA is widely used library automation software in the world and it has the provisions for all library operation. This paper appraised the implementation of Koha in Wollega University Library and went further to enumerate and discuss the challenges faced in the implementation of Koha and provided solutions to some of the challenges faced. This paper aims to elaborate the method of installation of koha, steps towards data migration from Excel to KOHA and upgrading process of KOHA version from 17.05 to 19.05.05. This is a descriptive paper of a case study conducted at Wollega University, Nekemte. The paper identifies several issues concerning data migration within a local scenario and elaborates how koha software installed and customised for university needs. The lesson learnt and the experience gained would stand to implement a similar kind of system at various places.
\end{abstract}

Keywords Library Automation, KOHA, Data Migration, Koha Customization

CONTACT Niranjana, K, Tolessa Desta and Paul N. Vijaya Kumar niranjanak@wollegauniversity.edu.et Department of Information Science, Wollega University, Nekemte, Ethiopia

2020 Authors Published with License by Information Impact

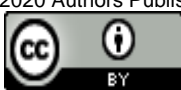




\section{Introduction}

The concept of library automation was evolved with advancement of information technology. The library automation is associated with the development and accomplishment of works that are done by specific machines. According to Kent, (1977) "Library Automation is the use of automatic and semiautomatic data processing machines to perform such traditional library activities as acquisitions, cataloguing and circulation. These activities are not necessarily performed in traditional ways, the activities themselves are those traditionally associated with libraries; library automation may thus be distinguished from related fields such as information retrieval, automatic indexing and abstracting and automatic textual analysis". In general, library automation describes a great paradigm shift in the system of management and the services of libraries to fulfil the requirements of clients.

Omeluzor et al., (2012) have stated that libraries in this period must prove to be the hub of academic activity, a dynamic system that will incorporate new and yet to be conceived features must be the focus. And further stated libraries of today must be aggressive to provide access to information within and outside the library through a viable system. A library system must ensure the security and accuracy of data to provide an effective and efficient service to its clients (Hettiarachchi \& Fernando, 2010). In any automated library system, data must have to be protected without any changes, addition, deletion and malformation. It is very important when move one system to another system where need to consider the data format and field compatibility.

\section{Automation History of Wollega University Library}

Wollega University (WU) is a public higher educational institution established in February 2007 by enrolling 851 students in 17 departments under four Faculties: Business and Economics, Education, Natural Sciences and Social Sciences. At present, Wollega University runs 82 undergraduate, 45 graduate programs and $5 \mathrm{PhD}$ programs in the three campuses. WU is an innovative institution and a pioneer University to implement continuous assessment, student-centered approach and active learning in the teaching-learning area to transform the traditional methods of teaching. Today, WU is a comprehensive University engaged in the provision of all-rounded education, research and community services.

\section{About Wollega University Main Library}

Wollega University Library and Documentation Service was set up in January 2007. The main goal of the Library is to back the university to achieve its goal of research-based, student-centered teaching-learning task and knowledge transfer. The Library is located in the main campus, Nekemte. It gives 24/7 full library, Internet and information service to 30,000 student population and more than 600 faculties. To fulfil the Vision and Mission of institution, beautiful library was established with initial collection of 3448 books and now it is rich with more than $45000+$ books and unique titles of 2500+ approx. 300 Bound Volumes of Journal. The university library has six departmental libraries different sections Circulation, Stock area, Reference Area with 200+ seating capacity in reference section and 60 Computer systems in the Network Resource Centre. 
The Wollega Univesity Main Library has started automation and migration of data works by using the koha integrated library management software on 2017. From May 2017, the library started to implement all modules of Koha like cataloguing, serial control, OPAC etc. The KOHA version 17.05 has been upgraded to KOHA 19.05 in September 2019 and added the new feature "email notification to users".

\section{KOHA Integrated Library Software (ILS)}

According to (Wikipedia, 2019) KOHA is a web based ILS with a SQL database (MySQL) backend, cataloguing data stored in MARC and accessible via Z39.50. KOHA user's interface is very configurable and adoptable which has been translated in to many languages. KOHA was initially developed in New Zealand by Katipo Communication Limited and first deployed in January 2000 for Horowhenua Library Trust (Pat, 2003). After the original implementation of KOHA, it has been adopted by thousands of libraries worldwide and each adding features and functions, deepening the capability of the software. Now the KOHA has state of the art web interface for clients and librarians, enriched content, faceted navigation, keyword searching, user contribution and Rich Site Summary (RSS) feeds. This was supported by Hassan, (2011) who argued that commercial vendors were not very supportive for library schools in offering their software at nominal cost/free of cost.

\section{Features of KOHA Software}

Koha is the first free software library automation package. In use worldwide, its development is steered by a growing community of users collaborating to achieve their technology goals. Koha's feature set continues to evolve and expand to meet the needs of its user base (Koha, 2019).

- Online public access catalogue (OPAC): The OPAC is web-based and there is no need to install any software on a user's machine.

- Web-based circulation interface: Can handle issues, returns, transfers, etc. There is no need to install any special software on staff computers once there is an intranet in place.

- Branches: Since the software is web-based it is easy to borrow a book in one branch and return it in another branch.

- Borrower history, comments and tags: Users can comment and review books, tag them and view their reading history. They can also view their records and make purchase suggestions.

- Customizable search: A library can choose the fields they want on their search form. For example, a search by author, title, subject, and keywords. There is also an advanced search option.

- Acquisitions: This includes orders from vendors, budgets, and pricing information.

- Serials: It allows easy cataloguing of journals and user can view holdings information through the OPAC.

- Multi-lingual OPAC support: KOHA allows patrons to view the OPAC in different languages depending on the language chosen by the library.

- Overdue fines and notices: KOHA manages overdue fines and notices that can be sent to users by email.

- Barcode printing and reader: KOHA fully supports the use of barcodes thereby removing the chances of human error.

- Reports and statistics. KOHA can generate management reports and statistics in cataloging, acquisitions, serials, and circulation 
- Koha is built using library standards and protocols such as MARC 21, UNIMARC, z39.50, SRU/SW, SIP2, SIP/NCIP, ensuring interoperability between Koha and other systems and technologies, while supporting existing workflows and tools.

In addition to the above features, the latest version contains some more new features. Some of them are news, label/user card creator, upload patrons images, task scheduler, overdue notices, log viewer, SQL builders, comments, export and import Biblio information, Mobile interface etc.

\section{Objectives of the Study}

$>$ To enumerate the experience of Wollega University, Nekemte Library in the implementation of KOHA.

$>$ To explain strategies towards migration of data from Excel to KOHA.

$>$ To suggest strategies for successful implementation of KOHA.

\section{Methodology}

This is a case study method conducted in Wollega University about how Koha integrated library management software implemented. This paper examines, technical infrastructure and Koha library software installation, customisation process and data migration process from excel sheet to MARC file. The study of the functioning of various modules of the software is reviewed by experiencing all the modules practically.

\section{Work plan}

A work plan was developed in order to implement KOHA installation successfully and cautious steps were taken to migrate data from the Excel sheet to KOHA. The recommended techniques were obtained through systematic search of available literature in this area to complete the task.

KOHA implementation was started in 2017 and it was scheduled to complete the conversion within 12 Months. The work plan developed with the consultation of consultant is as follows:

1. Installation and customization of KOHA version17.05

2. Google Input Tools: Translation to Amharic Language

3. Data editing

4. Data migration from excel sheet to KOHA 17.05

5. Training programme to the library staff

6. Implementing circulation module

7. Data security arrangement

8. Upgrading KOHA 17.05 to KOHA 19.05

\section{Implementation}

In 2017, the library academic committee has decided to implement KOHA Library Integrated Management System at the Library. In same year, a survey was carried out in order to identify the libraries which are using KOHA in other Government Universities, Ethiopia. An important study was carried out to identify the existing basic information regarding staff, collection and IT equipment in WU library. 
Table I, Table 2 and Table 3 show the basic information about the Wollega University Main library. The collection of WU library is multilingual, such as English, Amharic and Oromia.

\begin{tabular}{|c|c|c|}
\hline SI. No & Staff Details & Main Library \\
\hline 1 & Professional/ Academic staff & 02 \\
\hline 2 & Para professional staff & 15 \\
\hline 3 & Other Supportive Staff & 40 \\
\hline
\end{tabular}

Table 1. Basic information of WU main library Staff

Table 2. Collection Details in WU Main Library

\begin{tabular}{|c|c|c|}
\hline Sl. No. & Collection Details & Main Library \\
\hline 1 & Books & $45,000+$ \\
\hline 2 & CD's & $300+$ \\
\hline 3 & Journals and Periodicals & $46+$ \\
\hline 4 & News Papers & $16+$ \\
\hline 5 & Electronic Journals & 4 \\
\hline
\end{tabular}

\section{Hardware Procurement}

Since the Wollega University library doesn't have the server for installation of KOHA in 2017, a server with 16 GB RAM, 2TB HDD and Intel Xeon Processor, barcode readers, barcode stickers and backup device have been purchased to fulfil the hardware infrastructure. The required LAN and Internet connection also established to accomplish the network requirements.

Table 3. Basic information of WU library ICT cell IT Equipment

\begin{tabular}{|c|c|c|}
\hline SI. No. & IT Equipment & Main Library \\
\hline 1 & Server & 02 \\
\hline 2 & Personal Computers & 60 \\
\hline 3 & Scanners & 03 \\
\hline 4 & Barcode Readers or Scanners & 10 \\
\hline 5 & CC Camera & 08 \\
\hline 6 & Barcode Printer & 03 \\
\hline
\end{tabular}

\section{Installation and Customization of $\mathrm{KOHA}$ version 17.05}

Installation of Koha software in traditional way is complex job, many times library confronted with bugs and errors. Besides, library staffs were versatile about using of koha modules like Cataloguing, Acquisition, Serial Control etc. but not expert in installation aspect. Eventually, library discovered the Koha Live DVD which available at Koha Geek website. (Koha Geek, 2019) This Live DVD available in iso format and suitable for trial run, demonstration and installation. Later we downloaded the Live DVD iso file and extracted to DVD and run the software in "koha live dvd mode" in library server. To complete the installation of software executed the command "Uibiquity" in terminal, subsequently software installation screen was appeared. Installation of software consist simple steps like select the location, language for koha, finally software installed into the server computer.

OPAC and staff interface were customized to support and work with user requirement and that reflected the Wollega University. KOHA parameters such as item type, branch code, collection, circulation rule, member categories, fine rules etc. have been introduced and customized according to Library policy of the Wollega University. A new email was created for library(wollegalib@gmail.com), especially it helped to store koha backup in google drive and support to send alert messages for chekin, checkouts and overdue notices to users. 


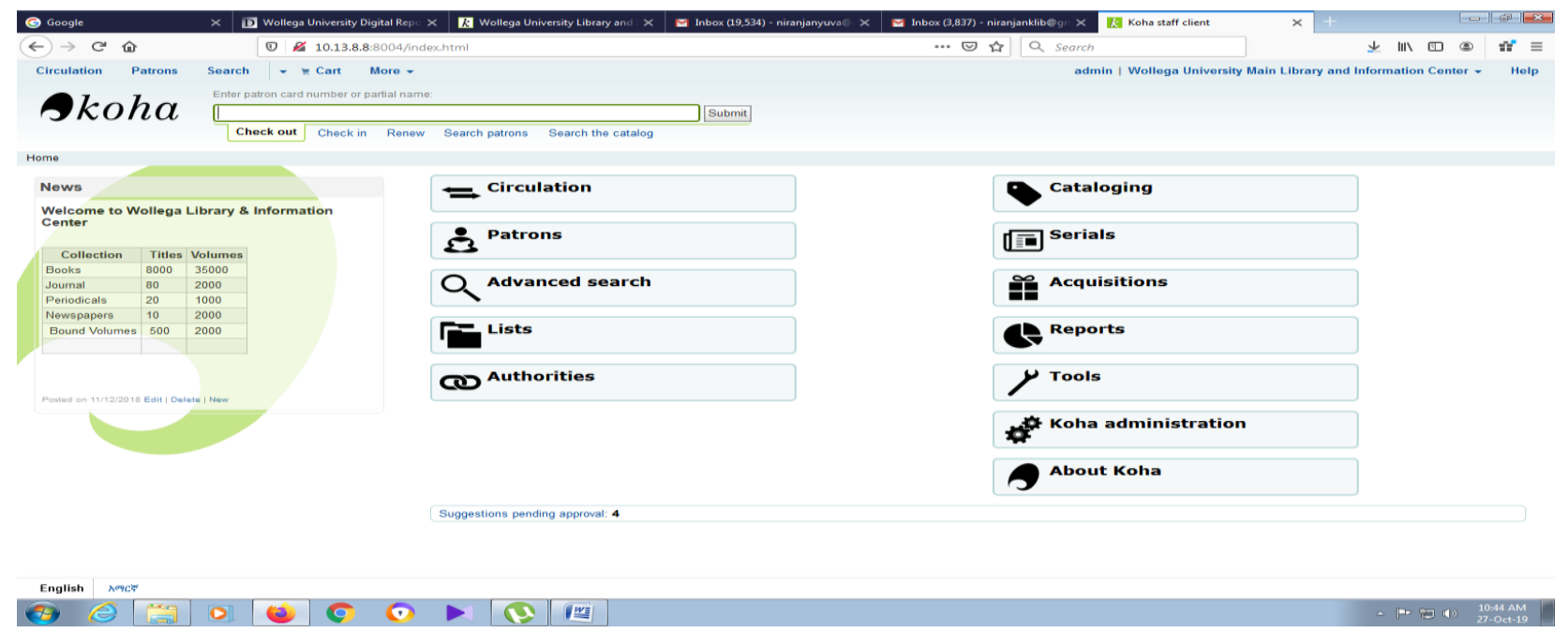

Figure 1.Home page of Koha at Wollega University Main Library.

\section{Google Input Tools: Translation to Amharic Language}

The Wollega University library had collections of non-Latin character languages such as Amharic etc. According to Google Input Tools, (2019) its helps to switch to typing in a different language with the click of the mouse, and switch back just as easily. The Google Input Tools extension provides virtual keyboards for over 90 languages, full IMEs or direct transliteration for over 30 different scripts, and handwriting input for over 40 languages. Thus "Google Input Tools" software has been installed in Chrome Browser of client PC to facilitate enter data in Amharic language. Also, barcode labels and printers procured to facilitate quick and easy access of the library materials during the circulation process like such as searching of library materials, stock taking, security etc.

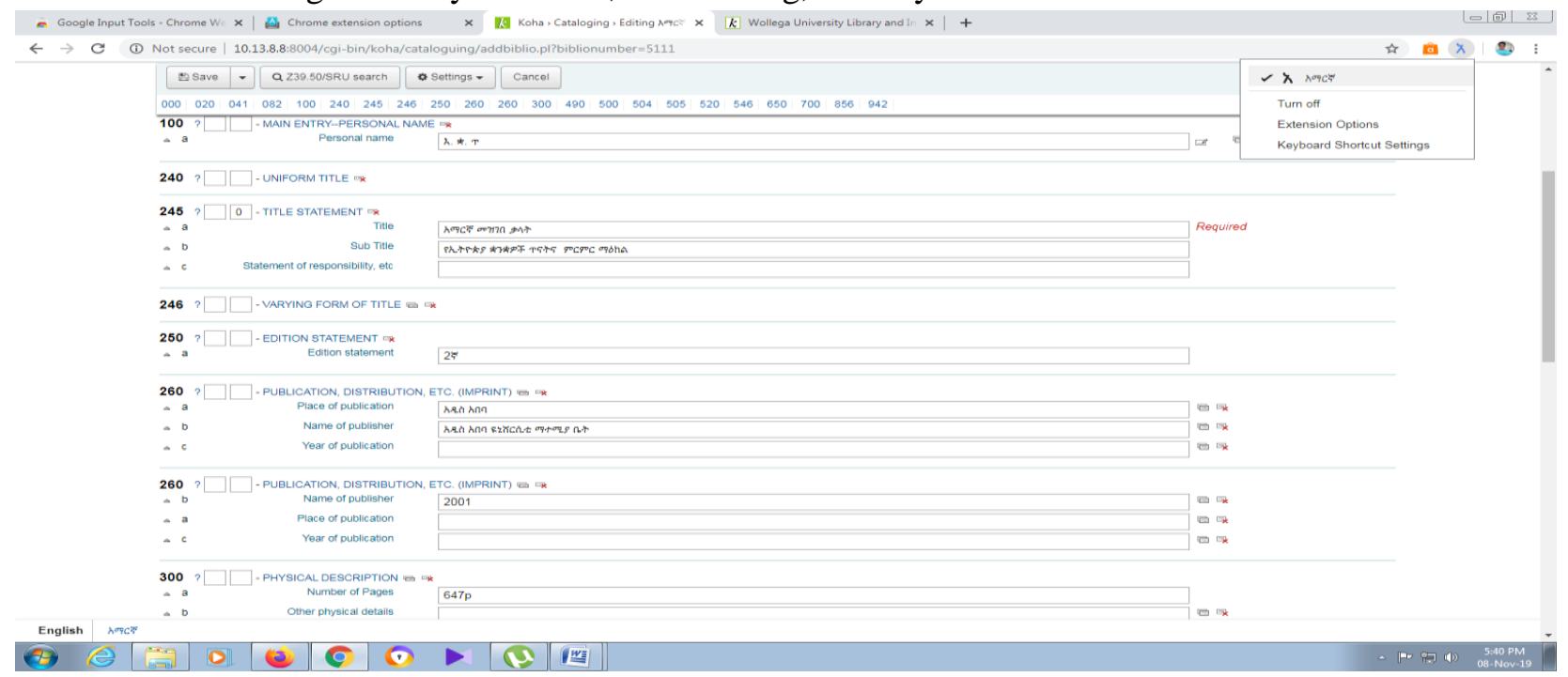

\section{Data migration from Excel to KOHA}

The migration of data from one system to another system is more crucial and some time it may complicated. In general, koha software supported to MARC format for migration of data. If we have the data like books in excel sheets needs to be convert into MARC format, then it is easy to export to KOHA. 
Moreover, WU library has identified that KOHA version 17.05 has major twelve tables according to bibliographic and MARC code information. Such as:

\section{MARC DATA ELEMENT}

1. ISBN

$020 \$ a$

2. Call No.

$082 \$ a$

3. Title

$245 \$ a$

4. Author

$100 \$ a$

5. Edition

$250 \$ a$

6. Place of Publication

$260 \$ a$

7. Publisher

$260 \$ b$

8. Year of Publisher

$260 \$ c$

9. No. of Pages

$300 \$ a$

10. Subject Added Entry

$650 \$ \mathrm{a}$

11. Type of Material $952 \$ y B K$

12. Accession Number or Barcode $952 \$ p$

The following steps were used for migration of data:

Step-01: Conversion of Excel Sheet Data

First step, in excel sheet we created twelve column for bibliographical data as follows for migration. shown in the figure 2.

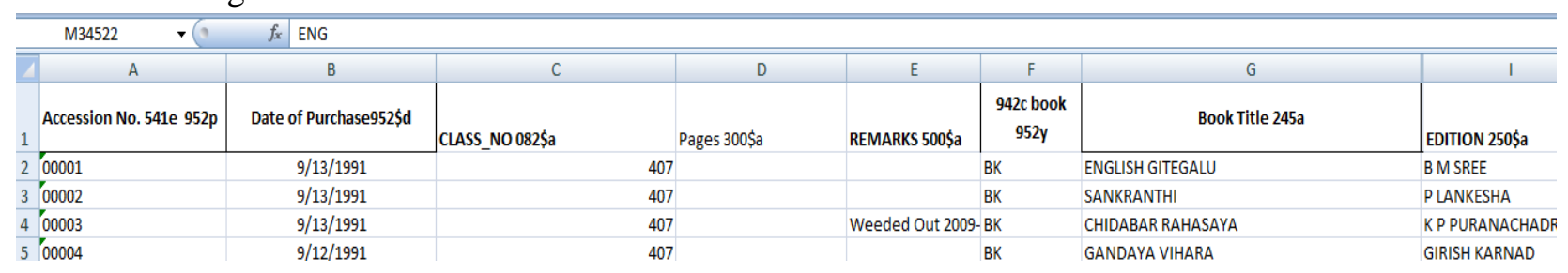

Figure 2. Sample print format used in Excel Sheet

Step-02: Convert this data sheet into tab delimited file.

In this step, we saved the excel sheet into .txt format. For this, we selected option save as in file option and save in .txt format. 


\begin{tabular}{|l|l|}
\hline 15429 & pavement analysis \$de \\
\hline 15428 & pavement analysis \$de \\
\hline 15436 & pavement analysis \$de \\
\hline 15600 & Structural steel design \\
\hline 15607 & Structural steel design \\
\hline 15602 & Structural steel design \\
\hline 15608 & Structural steel design \\
\hline 15591 & Structural steel design \\
\hline 15603 & Structural steel design \\
\hline 15599 & Structural steel design \\
\hline 15615 & Structural steel design \\
\hline 15614 & Structural steel design \\
\hline 15610 & Structural steel design \\
\hline 15605 & Structural steel design \\
\hline 15613 & Structural steel design \\
\hline 15609 & Structural steel design \\
\hline 15589 & Structural steel design \\
\hline 15593 & Structural steel design \\
\hline 15606 & Structural steel design \\
\hline 15598 & Structural steel design \\
\hline 15596 & Structural steel design \\
\hline 15597 & Structural steel design \\
\hline 15592 & Structural steel design \\
\hline 15601 & Structural steel design \\
\hline 15612 & Structural steel design \\
\hline
\end{tabular}

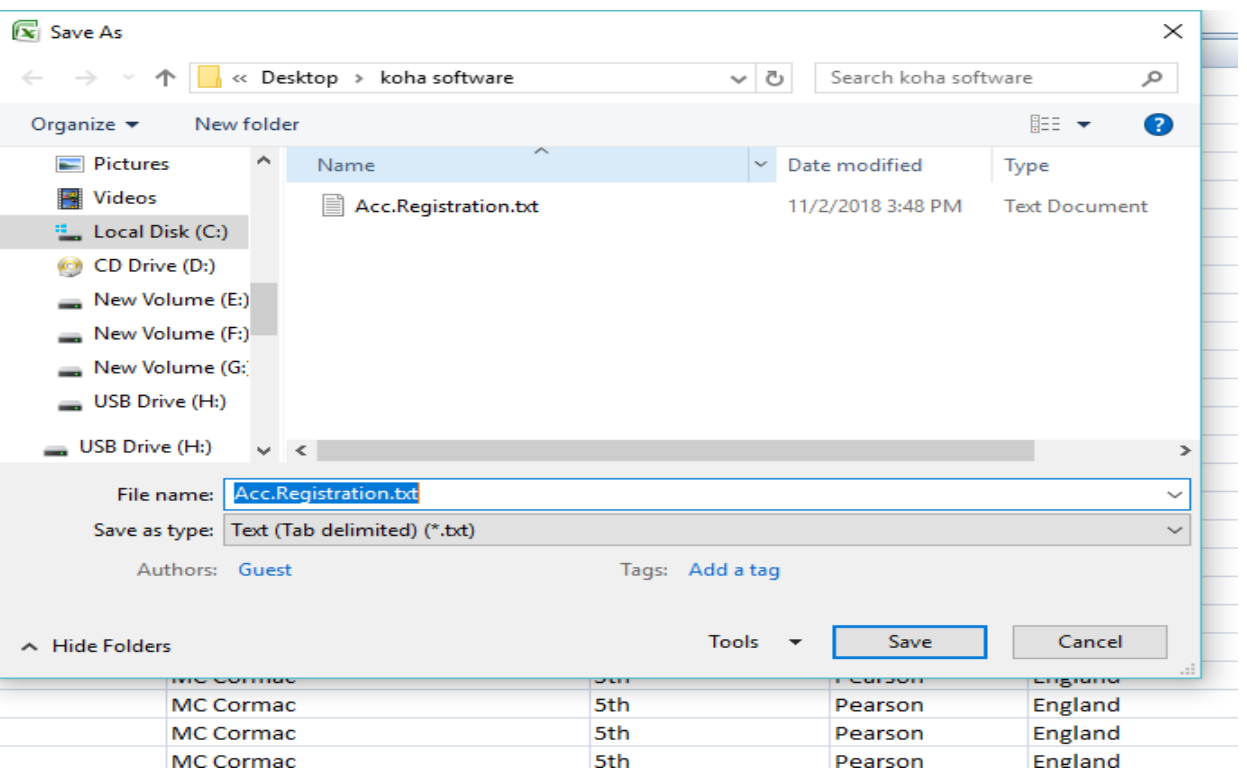

Figure 3. Converting excel sheet to .txt format.

Step-03: Installed "Marc Edit" software from internet in windows operating system. Then converted the tab delimited file into MARK format by using MARC edit software and succeeded to creating of MARK file.
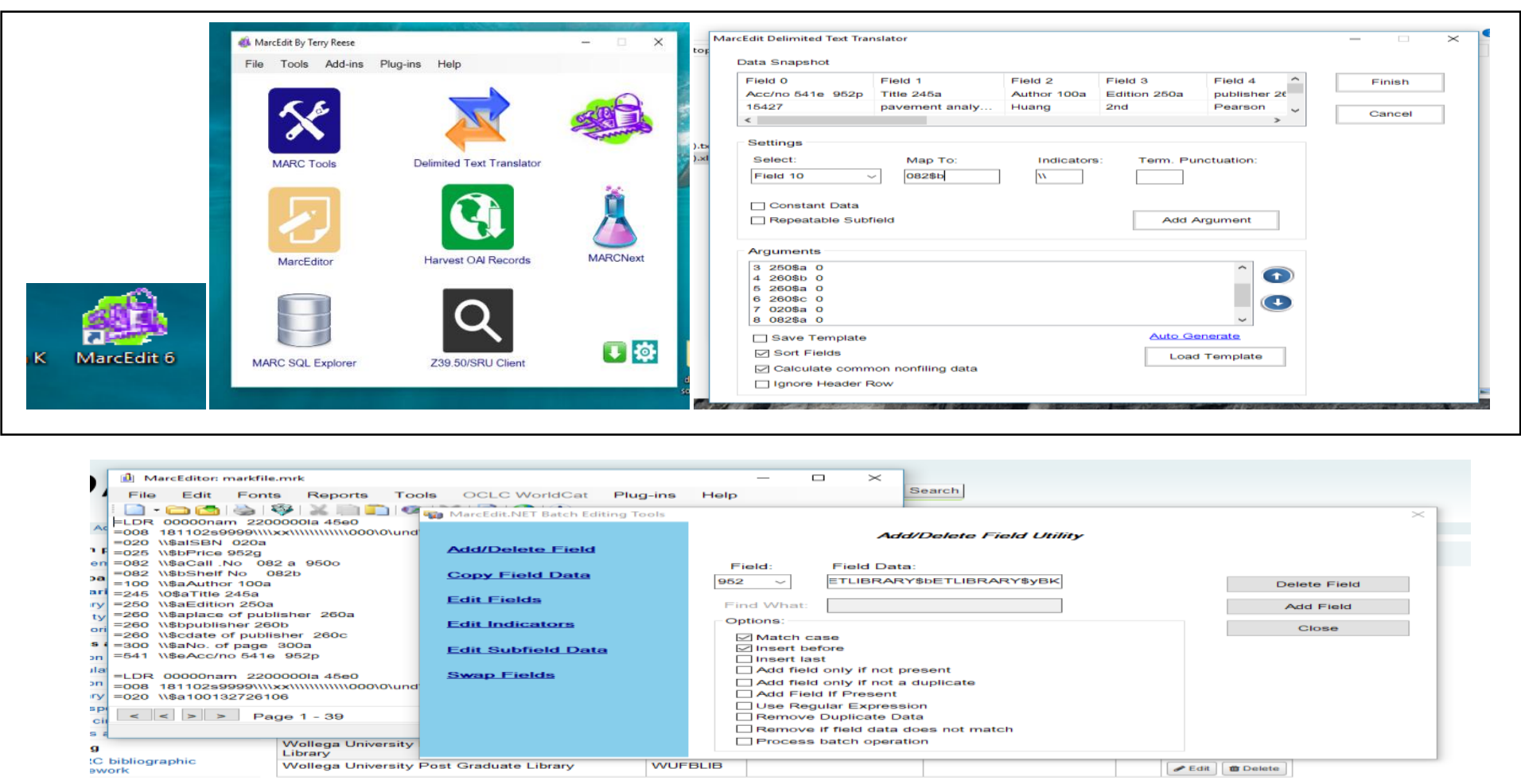

Figure 5. Converting to MARK to MARC format.

Step-04: Eventually, MARC file imported in koha software at Tools---> Stage Marc File, Result shows 45000 records staged. 


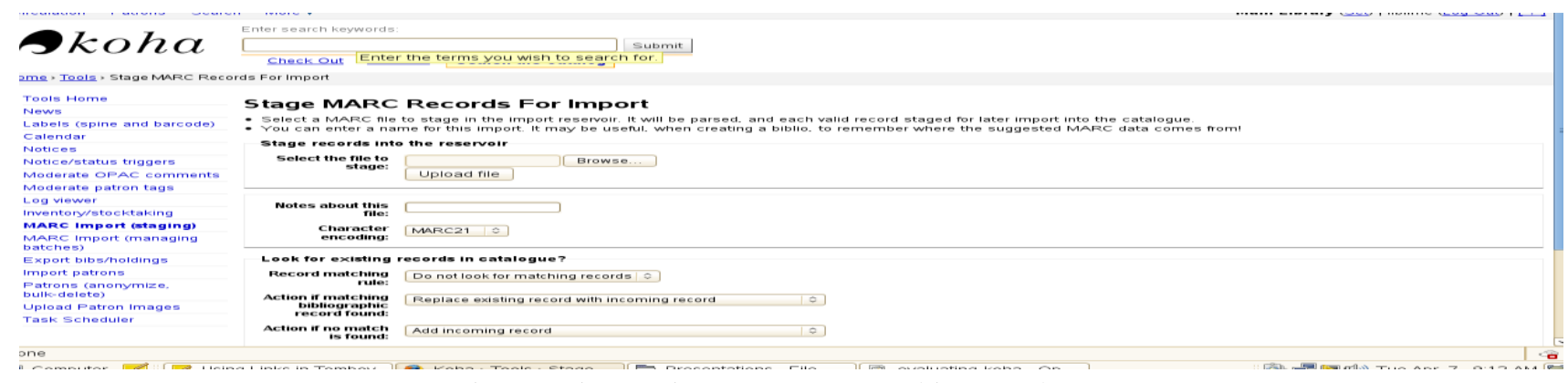

\section{Staff Training}

Figure 6.importing MARC record into Koha

A critical element to achieving success after an implementation program is to educate the users to effectively utilize the software. Igbena, (1990) defined user education as a process of making library patrons learn how to make effective and efficient use of library resources and information through the acquisition of skills in identification, location, search, retrieval and exploitation of information. Therefore, Staff training is an important activity for the successful implementation of KOHA automation process and it helps to uplift the skills of the library staff in library professional/Academics and paraprofessionals to well adopt to use the new software environment. Three training programmes were organized to educate how to use koha to user community. The first was the awareness training to whole library staff to elaborate the benefits and the necessity of using KOHA.

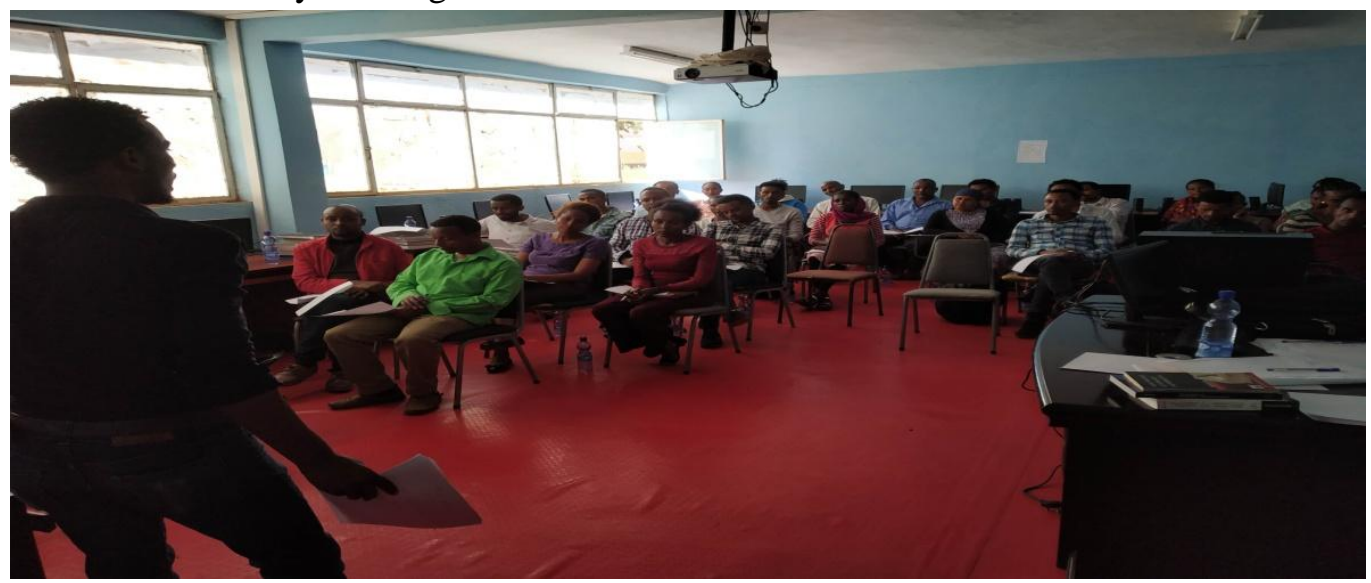

Figure 7. Staff training program at Wollega University

The second training included modules on installation of KOHA, customization of basic features, customization of all the modules such as cataloguing, members, circulation acquisition, serials and reports, existing data editing and editing of multilingual records. The third training on "hands on experience in circulation with KOHA" was scheduled just before starting the circulation modules and it was held in May 2018.

\section{Implementing Circulation Module}

Soon after completion of data editing, we have worked on to start the circulation module. The circulation has been started as shown in the following steps:

Step-01: Uploaded the patron information. It was done in the following ways; 
1. The user information was obtained from the administration of the University in Excel format and they were edited to match with the Borrowers table in the KOHA backend database.

2. The data were successfully exported using "patron_import.csv" which is available at Tools $\rightarrow$----$\rightarrow$ Patron import option in KOHA.

Step-02: We Customise the KOHA software in order to introduce new features which were not available in KOHA. Borrower activation privilege and deactivate the self-circulation for library staff were added to the system.

Step-03: The issuing and fine rules were setup based on the WU library circulation policy.

Step-04: For email notification, postfix software was installed in koha server computer. Fine rules and customised overdue notification has setup for automatic fine calculation and send the overdue notification

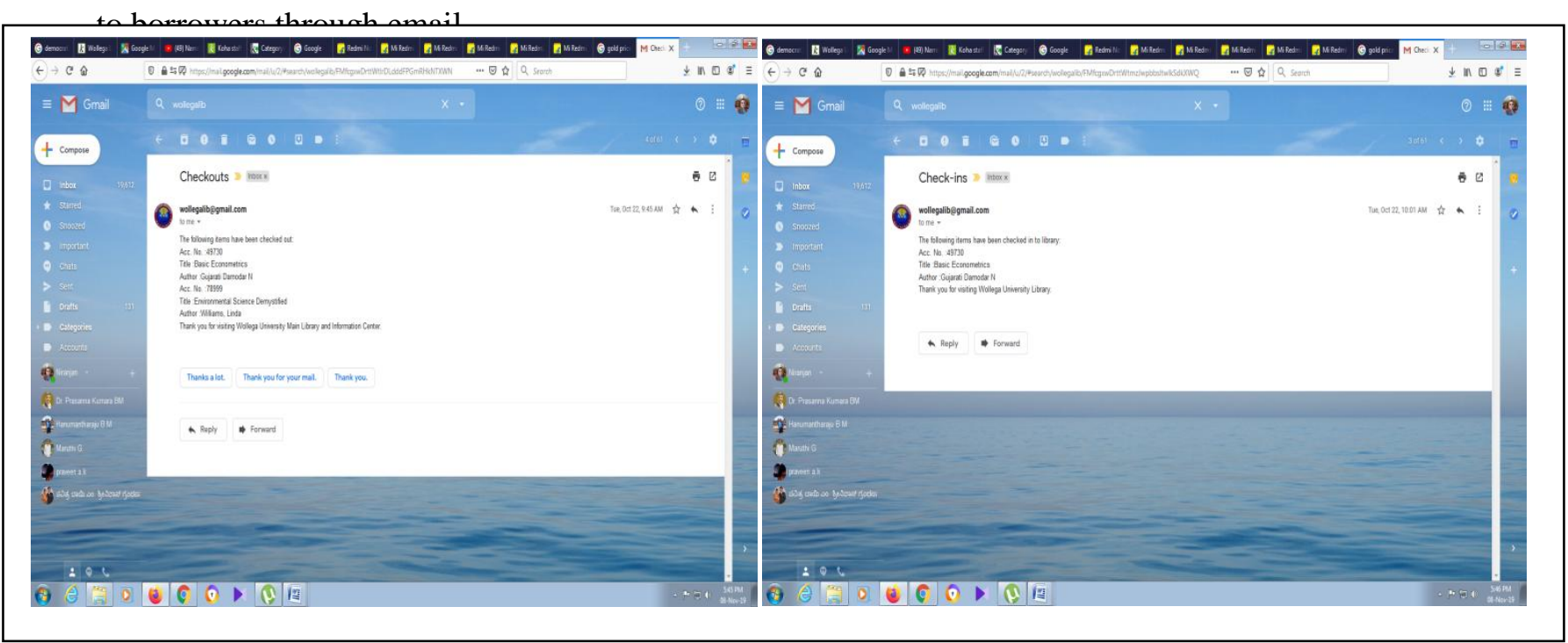

A separate email was created for easy and safe backup of Koha data. We open the google chrome and google drive in koha server computer and upload the backup data which is located at Koha Home $\rightarrow$ Backup $\rightarrow$ koha_library.sql.xz.

It is easy to get backup in command prompt. Go to Terminal $\rightarrow$ sudosu $\rightarrow$ (password) $\rightarrow$ mysqldump $-\mathrm{u}$ root -p koha_library-->backupfilename.sql $\rightarrow$ password(mysqlroot). After twenty second you will see the backup file "backupfilename.sql" in koha home page.

\section{Upgrading KOHA 17.05 to KOHA 19.05.05}

The WU library has moved to KOHA version 17.05 to 19.05.05 in September 2019. Normally, koha releases upgraded versions every six months consecutively. These upgraded versions removes the errors, bugs which appears at the earlier version. For upgrading koha we open the terminal and execute the commands as follows

Open terminal $\rightarrow$ sudosu $\rightarrow$ root password $\rightarrow$ sudo apt get-update $\rightarrow$ sudo apt get-upgrade $\rightarrow$ install koha commons

After executing this command newest upgraded version of Koha version installed to server computer. 


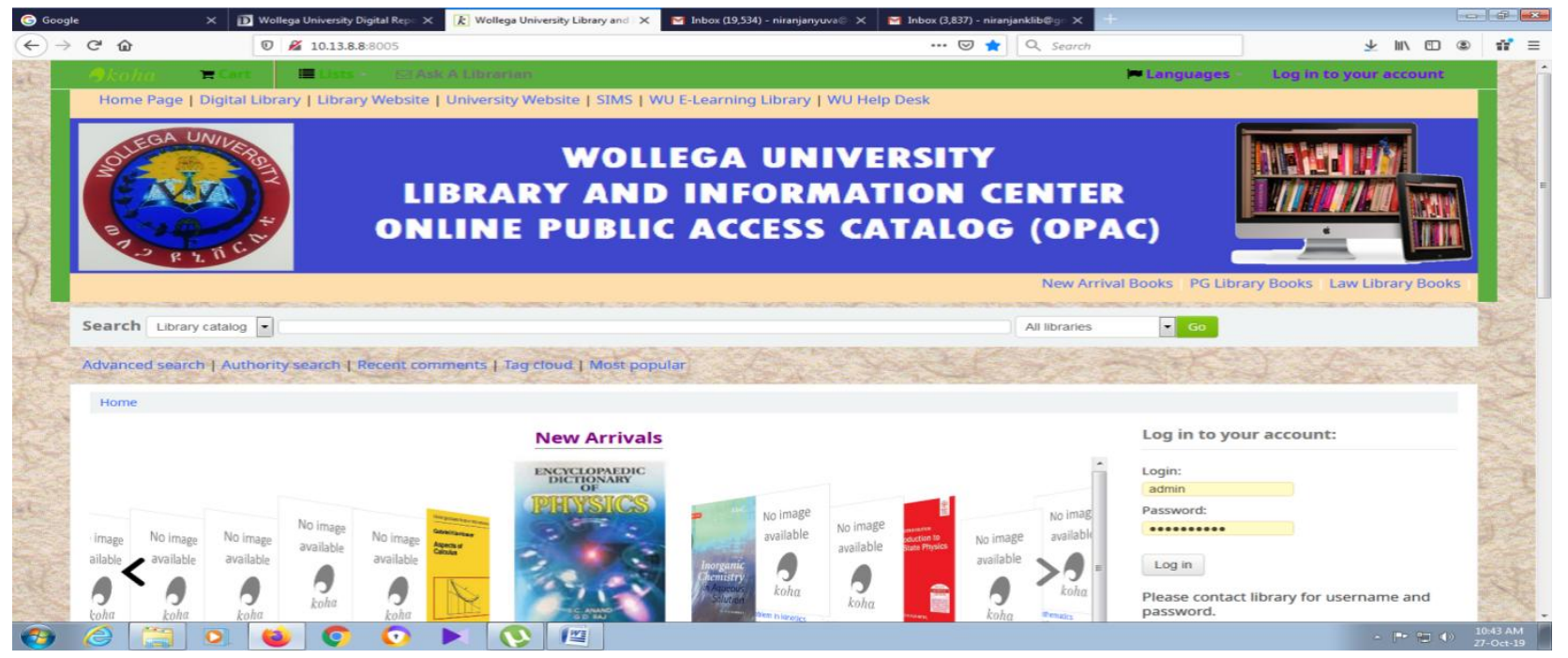

Figure 8. OPAC of the WU Library of the KOHA version 19.05.05

\section{Conclusion}

There is no doubt that automation of library activities enhances the library operations and services. The automation can improve the libraries' relevance to the academic community. However library automation requires adequate planning and technical support. Nahfees, Hettiarachchi and Rifaudeen, (2014) have stated that while converting the older system into any other new system, it is very much important to consider the factors which are critical. One of critical factors is that the data residing in the old system, we should ensure no data corrupt or lost while transforming into a new system.

The WU library succeeded the conversion of data from excel sheet to KOHA and KOHA version 17.05 to KOHA version 19.05.05 and the library perfectly adopted to use open source software. Therefore, it is ascertained that with the automation of library, Wollega University has achieved more economical benefits in terms of serving money to purchase commercial software and minimizing the maintenance cost of the software. On the investigation, the researchers find out that Koha software is suitable for automation of the library effectively. Further the library entered into to the global community and the library system can be viewed through the Internet. The lesson learnt and the experience gained could further be explored, documented and communicated to implement a similar kind of system at various places.

\section{References}

Aliyar M. N., Nimal H.I. \& Meera M. R, (2014). Implementation of koha integrated library management system in a multilingual environment of south eastern university of Sri Lanka: Third Annual Research Conference, Colombo, Sri Lanka, Colombo: ARC

Google Input Tools (2019). Add to Chrome. Retrieved from https://chrome.google.com/webstore/detail/google-input-tools/mclkkofklkfljcocdinagocijmpgbhab

Hassan, N. (2011). Issues and Challenges in Open Source Software Environment with Special Reference to India. Retrieved from http://crl.du.ac.in/ical09/papers/index_files/ ical-43_144_317_1_RV.pdf 
Hettiarachchi, N., \& Fernando, I.D.K.L (2010). Assuring the Security and Accuracy of Data Using a MySql Driven Database in an Automated Library Environment: Case Study for the Library of University of Ruhuna, 6th International Conference of the University Librarians Association, 2010. Colombo: ICULA

Igbena, F. A. (1990). User Education: A Comparative Analysis of UNN and Anambra State College of Education, Akwa (Unpublished BLS project) (pp. 19-20). University of Nigeria, Nsukka.

Koha (2019) Retrieved from https://koha-community.org/about/

Koha Geek. Live DVD (2019). Retrieved from http://kohageek.blogspot.com/p/live-dvd.html

Kent, Allen (1977). Encyclopedia of Library and Information Science. New York, NY: Marcel Dekkar.

Omeluzor, S.U., Adara, O. ,Ezinwayi, M. , \& Oby Umahi, F. (2012). Implementation of KOHA Integrated Library Management software (ILMS): The Babcock University Experience. Canadian Social Science, 8(4), 211-221. 